\title{
Cloning and Expression of Canine Interferon- $\alpha$ Genes in Escherichia coli
}

\author{
Osamu TAIRA ${ }^{1)}$, Itsuki WATANUGI ${ }^{1)}$, Yuko HAGIWARA ${ }^{1)}$, Masaki TAKAHASHI ${ }^{1)}$, Setsuo ARAI ${ }^{2}$, Hisaaki SATO ${ }^{1)}$ \\ and Nobutoshi MAEHARA ${ }^{1) *}$ \\ ${ }^{1)}$ Department of Veterinary Microbiology, School of Veterinary Medicine and Animal Sciences, Kitasato University, 23-35-1 Higashi, \\ Towada, Aomori 034-8628, and ${ }^{2)}$ The Kitasato Institute, 6-111 Arai, Kitamoto, Saitama 364-0026, Japan
}

(Received 28 March 2005/Accepted 16 June 2005)

ABSTRACT. We cloned five new subtypes of cDNA encoding canine interferon- $\alpha$ (CaIFN- $\alpha)$ from a canine epithelial cell line. CaIFN- $\alpha$ s were divided into two groups by amino acid sequences and a molecular phylogenic tree. Two subtypes of them were expressed in Escherichia coli, and IFN proteins were purified. Recombinant CaIFN- $\alpha$ s were highly species-specific and showed antiviral activity against Vesicular stomatitis New Jersey virus and canine adenovirus-1, but not against canine herpesvirus-1.

KEY WORDS: canine IFN- $\alpha$, cloning, expression.

J. Vet. Med. Sci. 67(10): 1059-1062, 2005

Interferon (IFN)s are small cellular polypeptides with a broad range of biological activities such as anti-viral, antiproliferative, and immunomodulating activity [2]. All mammals that have been studied have IFN $-\alpha$ and IFN- $\beta$ (type I) genes, and IFN- $\gamma$ (type II) genes. IFN- $\beta$ and IFN- $\gamma$ are animal species specific, but IFN- $\alpha$ has revealed antiviral activity on heterologous animal cells $[6,9]$.

Multiple subtypes of IFN- $\alpha$ have been detected in many mammalian species [7]. The cloning and expression of the cDNA for canine IFN- $\alpha(\mathrm{CaIFN}-\alpha)$ have been reported [4], but detailed descriptions are lacking.

To investigate the CaIFN- $\alpha$ in more detail, we attempted to clone multiple subtypes of the CaIFN- $\alpha$ gene from canine epithelial cells (MDCK) and expressed them in Esherichia coli.

MDCK cells were stimulated with the ultraviolet-irradiated B1 strain of Newcastle disease virus at multiplicity of infection of 30 for $6 \mathrm{hr}$. The total RNAs were extracted from stimulated cells using ISOGEN (Nippon Gene, Tokyo, Japan). cDNA was synthesized from mRNA in the presence of oligo dT and AMV Reverse Transcriptase XL (TaKaRa Bio. Inc., Shiga, Japan), and used as a template to clone CaIFN- $\alpha$ cDNA. The primers used for amplification were derived from GenBank (accession (GBA) Nos. J00210, I46204 and M10952). The sense primer was a 27-mer consisting of the sequence 5'-GCGGATCCATCTTCAGGATCCCCGATG-3'. The anti-sense primer was a 27-mer consisting of the sequence 5'-CGAAGCTTGTCAGAGAGAGAATCATTTCC-3'; the BamHI and HindIII restriction sites are indicated as underlines, respectively. The polymerase chain reaction (PCR) conditions included a 2 min denaturation step at $94^{\circ} \mathrm{C}$ followed by 30 cycles of 30 sec at $94^{\circ} \mathrm{C}, 30 \mathrm{sec}$ at $55^{\circ} \mathrm{C}$, and at $72^{\circ} \mathrm{C}$ for $2 \mathrm{~min}$. A final extension for $10 \mathrm{~min}$ at $72^{\circ} \mathrm{C}$ was then performed. The PCR products were digested with BamHI and HindIII, and ligated

\footnotetext{
* Correspondence to: Dr. Maehara, N., Department of Microbiology, School of Veterinary Medicine and Animal Sciences, Kitasato University, 23-35-1 Higashi, Towada, Aomori 034-8628, Japan.
}

into a pUC18 vector.

The recombinant plasmid was transformed into $E$. coli strain XL1-blue. The isolation of the plasmid DNA was performed according to the manufacturer's protocol using a GFX Micro Plasmid Prep Kit (Amersham Biosciences). The nucleotide sequencing was carried out with a DNA Sequencing Kit (Big Dye Terminator Cycle Sequencing Ready Reaction, Applied Biosystems INC. (ABI); Foster City, CA, U.S.A.) and an ABI PRISM 310 Genetic Analyzer (ABI) according to the manufacturer's instructions. Computer-assisted sequence analysis was carried out with GENETYX-MAC 10.1, a software package (Genetyx Inc., Tokyo, Japan). Phylogenic analysis was performed by N-J method using GENETYX-WIN7 (Genetyx Inc.).

The PCR primers for the expression of CaIFN- $\alpha$ were designed based on the sequence of CaIFN- $\alpha 7$ and CaIFN$\alpha 8$. The sense and anti-sense PCR primers were designed to regions +70 to +90 (with the +1 position corresponding to the initiation codon of the signal peptide) and +558 to +584 of the CaIFN- $\alpha 7$ and CaIFN- $\alpha 8$ genes. The sense primer was 29-mer and consisted of the sequence 5'-CGGGATCCTGCCACCTGCCCGACACCCAC-3'. The anti-sense primer was a 26-mer consisting of the sequence 5'-GCGTCGACTTGAACCTGGTCTCATTC-3'; the BamHI and SalI restriction sites are indicated as underlines, respectively. The PCR conditions included a 2 min denaturation step at $94^{\circ} \mathrm{C}$, followed by 30 cycles of $30 \mathrm{sec}$ at $94^{\circ} \mathrm{C}, 30 \mathrm{sec}$ at $60^{\circ} \mathrm{C}$, and $2 \mathrm{~min}$ at $72^{\circ} \mathrm{C}$. A final extension for $10 \mathrm{~min}$ at $72^{\circ} \mathrm{C}$ was then performed. The PCR products were ligated between the BamHI and SalI restriction sites of the pMALc2x expression vector (New England BioLabs, Inc., Beverly, MA.).

The expression vector was transformed into the $E$. coli strain TOP10. The expression of recombinant proteins was performed according to the manufacturer's protocols, using a pMAL Protein Fusion and Purification System (New England BioLabs, Inc., Beverly, MA.). The purity of rCaIFN- $\alpha 7$ and rCaIFN- $\alpha 8$ were checked on sodium dodecyl sulfate polyacrylamide gel electrophoresis (SDS-PAGE) 


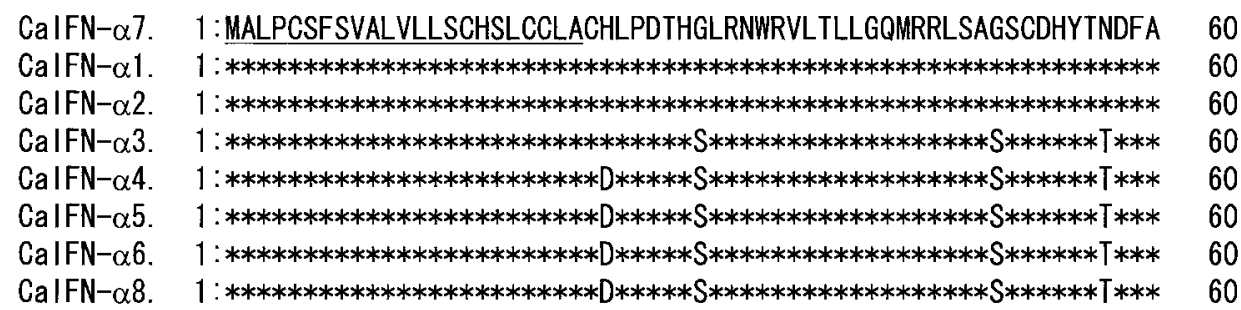

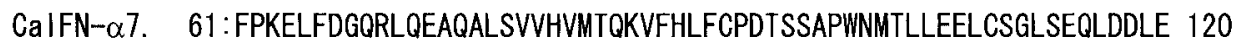

CaIFN- 1 1. $61: * * * * * * * * * * * * * * * * * * * * * * * * * * * * * * * * * * * * * * * * * * * * * * * * * * * * * * * * * * * * * * * * 120$

CalFN- 2 2. $61: * * * * * * * * * * * * * * * * * * * * * * * * * * * * * * * * * * * * * * * * * * * * * * * * * * * * * * * * * * * * * * * * * * 120$

CaIFN- $23 . \quad 61: * * * * * * * * * * * * * * * * * * * * * * * * * * * * * * * * * \mathrm{IN} N * * * * * * * * * * * * * * * * * * * * * * * * * * * * \mathrm{D} 120$

CalFN- $24 . \quad 61: * * * * * * * * * * * * * * * * * * * * * * * * * * * * * * * * * * * * \mathrm{TNM} M * * * * * * * * * * * * * * * * * * * * * * * * * * \mathrm{D} 120$

CaIFN- $\alpha 5 . \quad 61: * * * * * * * * * * * * * * * * * * * * * * * * * * * * * * * * \mathrm{TNM} * * * * * * * * * * * * * * * * * * * * * * * * * * \mathrm{D} 120$

CalFN- $66 . \quad 61: * * * * * * * * * * * * * * * * * * * * * * * * * * * * * * * * * * * T \mathrm{TM} M * * * * * * * * * * * * * * * * * * * * * * * * * * * \mathrm{D} 120$

$\mathrm{CaIFN}-\alpha 8 . \quad 61: * * * * * * * * * * * * * * * * * * * * * * * * * * * * * * * * * * * \mathrm{TNM} M * * * * * * * * * * \mathrm{G} * * * * * * * * * * * * * * \mathrm{D} 120$

CaIFN- 7 7. 121: ACPLQEAGLAETPLMHEDSTLRTYFQR I SLYLQDRNHSPCAWEMVRAEIGRSFFSSTILQ 180

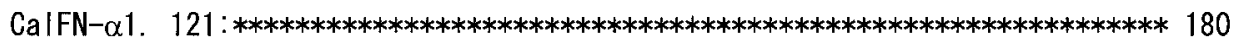

CaIFN- 2 2. $121: * * * * * * * * * * * * * * * * * * * * * * * * * * * * * * * * * * * * * * * * * * * * * * * * * * * * * * * * * * * * * * * * * * * * 180$

CaIFN- $33.121: * * * * * * * * * * * * * * * * * * * * * * * * * * * * * * * * * * * * * * * * * * * * * * * * * * * * * * * * * * * * * L * * * * * 180$

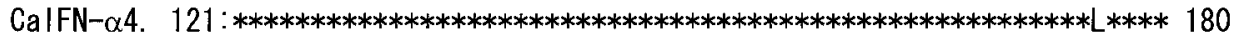

CaIFN- $\alpha 5 . \quad 121: * * * * * * * * * * * * * * * * * * * * * * * * * * * * * * * * * * * * * * * * * * * * * * * * * * * * * * * * * * * * * * \mathrm{~L} * * * \mathrm{R} 180$

CaIFN- $\alpha 6 . \quad 121: * * * * * * * * * * * * * * * * * * * * * * * * * * * * * * * * * * * * * * * * * * * * * * * * * * * * * * * * * * * * * L * * * * * 180$

CaIFN- $28 . \quad 121: * * * * * * * * * * * * * * * * * * * * * * * * * * * * * * * * * * * * * * * * * * * * * * * * * * * * * * * * * * * L * * * * * 180$

$\begin{array}{ll}\text { CaIFN- } \alpha 7.181: \text { ERIRRKE } & 187\end{array}$

$\begin{array}{ll}\text { CaIFN- }-1.181: * * * * * R K & 187\end{array}$

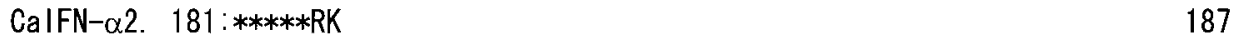

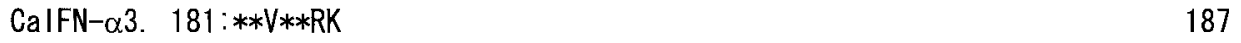

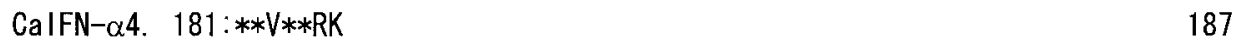

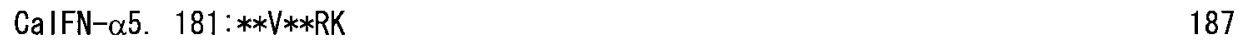

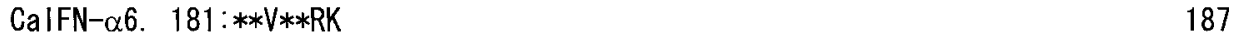

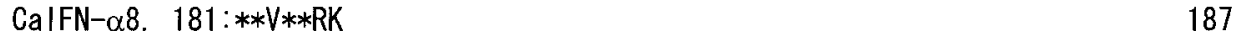

Fig. 1. Amino acid sequence homology among the CaIFN- $\alpha$ subtypes. CaIFN- $\alpha 1,2,3$ are already reported. Under line indicated signal sequence.

and visualized by Coomassie brilliant blue R-250 (CBB R250; E Merck AG Co. Ltd., Dermstadt, Germany).

The activity of rCaIFN- $\alpha$ was determined by the cytopathic effect (CPE) inhibition assay using Vesicular stomatitis New Jersey virus (VSV) on the MDCK, A72, Cf2Th, MDBK, RK-13, and fcwf-4 cells [3]. In addition, the antiviral activities for canine herpes virus-1(CHV-1) and canine adenovirus-1(CAV-1) were measured on the MDCK cell.

We cloned five different subtypes of CaIFN- $\alpha$ cDNA (each CaIFN- $\alpha$ s GBA Nos. were AB102731: CaIFN- $\alpha 4$, AB125934: CaIFN- $\alpha 5$, AB125935: CaIFN- $\alpha 6$, AB125936: CaIFN- $\alpha$ 7, and AB125937: CaIFN- $\alpha 8)$. Their open reading frames (ORF) were $564 \mathrm{bps}$, and the gene encoded a signal sequence of 23 aa and a mature protein of 164 aa (Fig. 1).

CaIFN- $\alpha$ contains six cysteine residues (cys). The homology of the aa sequences among CaIFN- $\alpha 4-8$ and the previously reported subtypes (CaIFN- $\alpha 1-3)$ were 93$100 \%$. Mutations among these subtypes were occurred at 14 positions. From the molecular phylogenetic tree, CaIFN- $\alpha$ s were divided into two groups; Group I included CaIFN- $\alpha 1$, 2, and 7 and group II included CaIFN- $\alpha 3,4,5,6$ and 8 (Fig. 2). Amino acid changes from group I to group II were seen at positions 25 (His to Asp), 31 (Gly to Ser), 49 (Gly to Ser), 57 (Asn to Thr), 93 (Pro to Thr), 94 (Asp to Asn), 120 (Glu to Asp), 175 (Ser to Leu) and 183 (Ile to Val) (Fig. 1).

The SDS-PAGE patterns of rCaIFN- $\alpha 7$ and rCaIFN- $\alpha 8$ are shown in Fig. 3. Each rCaIFN- $\alpha$ was treated with FactorXa and purified by the pMAL Protein Fusion and Purification System. rCaIFN- $\alpha 7$ and $\mathrm{rCaIFN}-\alpha 8$ showed one visible band with apparent molecular weights of about 20 $\mathrm{kDa}$, respectively.

rCaIFN- $\alpha 7$ and $\mathrm{rCaIFN}-\alpha 8$ showed antiviral activities on the three kinds of canine cells; MDCK, A72 and Cf2Th, but not on the heterologous cells, MDBK (bovine), RK-13 (rabbit) and fcwf-4 (feline) (Table 1). rCaIFN- $\alpha 7$ was $4-5$ fold more active than rCaIFN- $\alpha 8$ on the canine cells. rCaIFN- $\alpha$ s 


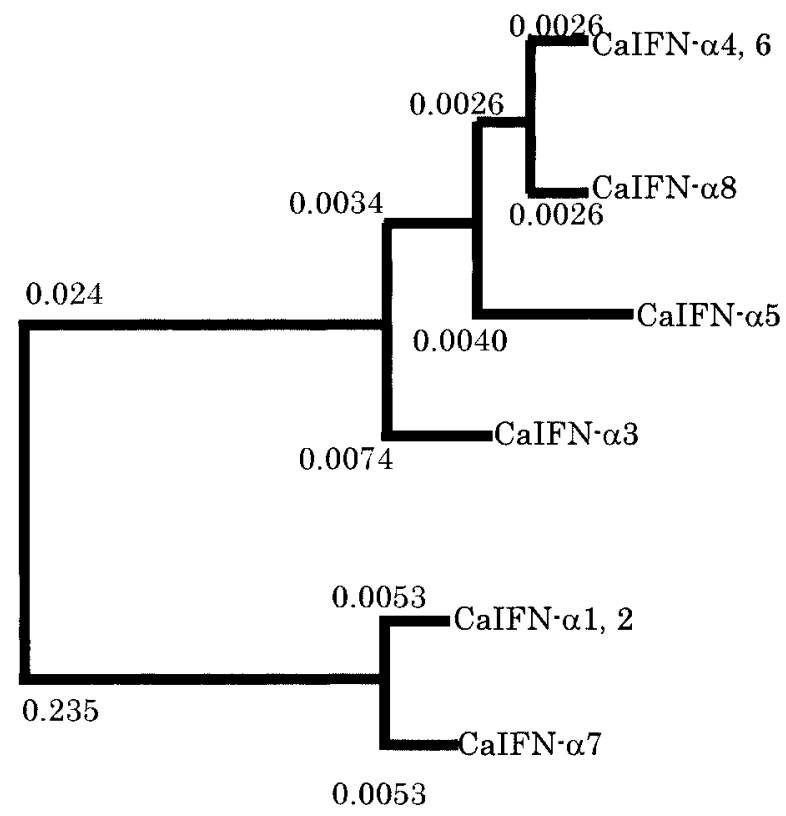

Fig. 2. Molecular phylogenic tree based on amino acid sequence of CaIFN- $\alpha$ subtypes.

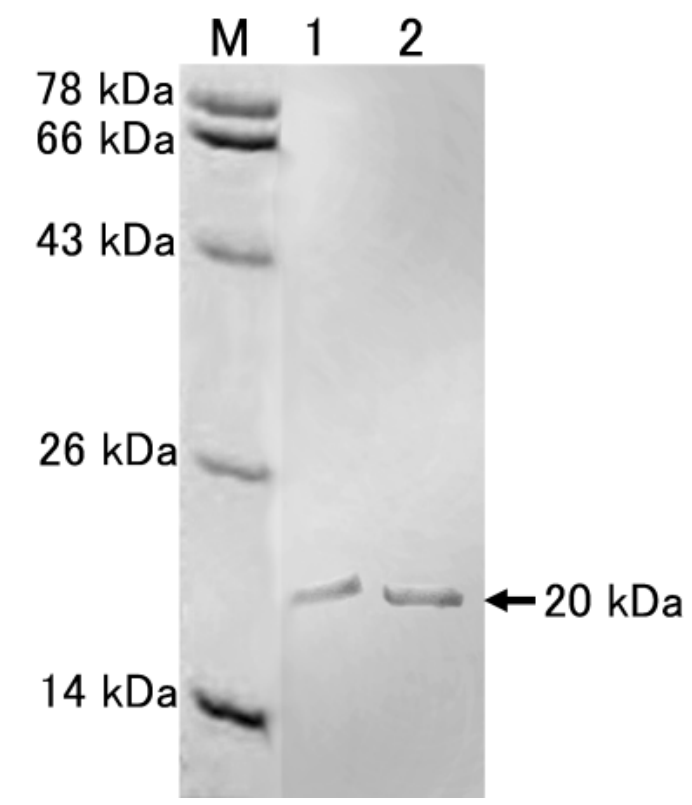

Fig. 3. SDS-PAGE analyses of purified CaIFN- $\alpha 7$ and 8. The proteins were stained with Coomassie brilliant blue R-250 after electrophoresis. Lane 1, rCaIFN- $\alpha 7$; lane 2 , rCaIFN- $\alpha 8$; lane $\mathrm{M}$, molecular marker.

Table 1. Antiviral activities of rCaIFN- $\alpha$ against VSV on the various animal cells

\begin{tabular}{ccccccc}
\hline & \multicolumn{6}{c}{ Antiviral activity $\left(\times 10^{6} \mathrm{U} / \mathrm{mg}\right)$ on the cells } \\
\cline { 2 - 7 } IFN & MDCK & A72 & Cf2Th & MDBK & RK-13 & fcwf-4 \\
\hline rCaIFN- $\alpha 7$ & 20.00 & 5.10 & 1.30 & $<0.000001$ & $<0.000001$ & $<0.000001$ \\
rCaIFN- $\alpha 8$ & 5.10 & 1.30 & 0.32 & $<0.000001$ & $<0.000001$ & $<0.000001$ \\
\hline
\end{tabular}

were the most active on the MDCK cells and the least active on the Cf2Th cells. rCaIFN- $\alpha$ s were tested for antiviral activities against VSV, CAV-1 and CHV-1 on the MDCK cells (Table 2). rCaIFN- $\alpha 7$ and rCaIFN- $\alpha 8$ showed antiviral activities against VSV and CAV-1 but not against CHV1. rCaIFN- $\alpha$ s were 39 or 666 fold more active against VSV than CAV-1.

Among the six cystein residues in the mature protein, four (at positions 24, 52, 122 and 154) were conserved in all mammalian IFN- $\alpha$. An S-S bond was formed between the cysteine residues located in 24 and 122, 52 and 160, and served to stabilize the molecule [7]. Two extra cysteine residues (at positions 92 and 109) were contained in only CaIFN- $\alpha$ and FeIFN- $\alpha$ [5]. CaIFN- $\alpha$ had $63.5 \%$ aa homology between FeIFN- $\alpha$ and the value was much higher than that between bovine IFN- $\alpha$ (54.1\%, GBA Nos.: M10952, M10953, M10954, M10955, M11001, X93087, X93088, X93089), porcine IFN- $\alpha$ (52.7\%, GBA No.: X57191.1), human (Hu) IFN- $\alpha(52.7 \%)$ [11] and murine (Mu) IFN- $\alpha$ (49.2\%, GBA Nos.: D00460, M13660, M13710, X01969, X01971, X01972, X01973, X01974).

Among the 8 subtypes of CaIFN- $\alpha$, variations of aa existed at 14 positions, and the homology of each CaIFN- $\alpha$
Table 2. Antiviral activities of $\mathrm{rCaIFN}-\alpha$ against viruses on the MDCK cell

\begin{tabular}{lccc}
\hline & \multicolumn{3}{c}{ Antiviral activity $\left(\times 10^{6} \mathrm{U} / \mathrm{mg}\right)$} \\
\cline { 2 - 4 } IFN & VSV & CAV-1 & CHV-1 \\
\hline rCaIFN- $\alpha 7$ & 20.00 & 0.03 & $<0.000001$ \\
rCaIFN- $\alpha 8$ & 5.10 & 0.13 & $<0.000001$ \\
\hline
\end{tabular}

subtype ranged from 93 to $100 \%$. The variations of aa among the subtypes of CaIFN- $\alpha$ were much smaller than those of human, murine, and bovine IFN- $\alpha$ s, but were similar to FeIFN- $\alpha$. Among the 21 subtypes of HuIFN- $\alpha$, variations of aa existed at 101 different positions, and the homology of each HuIFN- $\alpha$ subtype ranged from $82.5 \%$ to $96.8 \%[5,11]$. Similarly, MuIFN- $\alpha$ had variations at 63 positions among the 8 subtypes and BoIFN- $\alpha$ had variations at 34 positions among the 8 subtypes[5]. FeIFN- $\alpha$ had variations of aa at 10 positions among 14 subtypes and had the homology of each subtype ranged from 94.3 to $99.5 \%$ [5]; the values are similar to CaIFN- $\alpha$.

CaIFN- $\alpha$ s were divided into two groups with aa changes at 9 points. Both of CaIFN- $\alpha 7$ and CaIFN- $\alpha 8$ belong to a 
different group showing antiviral activity on the canine cells but not on the bovine, rabbit and feline cells. The high titer of rCaIFN- $\alpha 7$ with $2 \times 10^{7} \mathrm{U} / \mathrm{mg}$ of antiviral activity on the MDCK cells did not show any activity on the heterologous animal cells. Crude rCaIFN- $\alpha$ with a low titer $(300 \mathrm{U} / \mathrm{m} l)$ of antiviral activity did not have any activity on human or equine cells, as has also been reported [4]. In contrast, rHuIFN- $\alpha$ showed antiviral activity on bovine, porcine, equine, murine, and feline cells $[1,3,8,9]$. The antiviral activities of IFN- $\alpha$ subtypes on homologous and heterologous animal cells correlated with the binding affinity of them to specific cell-surface receptors [1].

rCaIFN- $\alpha$ s were highly active $\left(5-20 \times 10^{6} \mathrm{U} / \mathrm{m} l\right)$ against VSV, 33-666 fold less active against CAV-1 than VSV, and did not show any activity against CHV-1.

\section{REFERENCES}

1. Aguet, M., Grobke, M. and Dreiding, P. 1984. Virology 132: 211-216.

2. Baron, S., Coppenhaver, D. H., Dianzani, F., Fleischman, W. R., Hugh, T. K., Klimpel, G. R., Niesel. D. W., Stanton, G. J. and Tyring, S. K. 1992. pp. 1-15. In: Interferon: Principles and Medical Aplications (Baron, S. et al. eds.), Univ. Texas Med.
Branch at Galveston, Galveston.

3. Bridgman, R., Rossi, C. R. and Campos, M. 1988. J. Interferon Res. 8: 1-6.

4. Himmler, A., Hauptmann, R., Adolf, G. R. and Swetly, P. 1987. J. Interferon Res. 7: 173-183.

5. Nagai, A., Taira, O., Ishikawa, M., Hiramatsu, K., Hohdatsu, T., Koyama, H., Arai, S., Sato, H., Nakano, K. and Maehara, N. 2004. J. Vet. Med. Sci. 66: 725-728.

6. Nagano, Y. and Maehara, N. 1975. Jpn. J. Microbiol. 19: 447448.

7. Roberts, R. M., Liu, L., Guo, Q., Leaman, D. and Bixby, J. 1998. J. Interferon Cytokine Res. 18: 805-816.

8. Sen, G. C., Herz, R., Davatelis, V. and Pestka, S. 1984. J. Virol. 50: 445-450.

9. Werenne, J., Pastoret, P. D., Broecke, C. V., Schwers, A., Goosens, A., Bugyaki, L. and Maenhound, M. 1983. pp. 419424. In: The Biology of the Interferon System (De Maeyer, E. and Schellekens H. eds.). Elsevier Science Publishers, Amsterdam.

10. Wonderling, R., Powell, T., Baldwin, S., Morales, T., Snyder, S., Keiser, K., Hunter, S., Best, E., McDermott, M. J. and Milhausen, M. 2002. Vet. Immunol. Immunopathol. 89: 13-27.

11. Zoon, K. C., Bekisz, J. and Miller, D. 1992. pp. 95-105. In: Interferon: Principles and Medical Aplications (Baron, S. et al. eds.), Univ. Texas Med. Branch at Galveston, Galveston. 